\title{
Study on the Optimization and Adjustment of Professional Structure of Higher Vocational Colleges in the Pearl River Delta Under the Background of Constructing Modern Economic System
}

\author{
Based on the Perspective of the Functional Urban Specialization*
}

\author{
Hailong Lin \\ Qingyuan Polytechnic \\ Qingyuan, China 511510
}

\begin{abstract}
At present, China is in the process of transforming its development mode, optimizing its economic structure, and transforming its growth momentum. The national and regional economic development models and development directions are all dynamically adjusted. From the perspective of functional urban specialization, this paper studies the way to perfect the professional system of higher vocational colleges and make it well connected with the local economic system, by constructing a synergy coefficient to measure the level of professional structure and industrial structure of the Pearl River Delta urban agglomeration, and combining the requirements of modern economic system construction for talent structure adjustment. It can also provide theoretical and empirical evidence for the training of higher vocational education personnel and the coordinated development of regional industrial structure.
\end{abstract}

Keywords-professional structure of higher vocational education; industrial structure; synergy coefficient; functional specialization

\section{INTRODUCTION}

At present and for some time to come, China is in an important stage of economic transformation, structural adjustment and industrial upgrading. Building a modern economic system is the strategic goal of China's development, and it is also an urgent requirement for transforming the economic development mode, optimizing the economic structure, and transforming the economic growth momentum. The industrial system is an important part of the production process of the economic system. The modern industrial system should be composed of high-end, high value-added, technology and knowledge-intensive industries in the global value chain, representing the

*Project Source: 2018 Guangdong Academy of Social Sciences Branch Project: Research on the Allocation of High-quality Education Resources in Qingyuan City from the Perspective of Equalization of Public Services; 2018 Qingyuan Science and Technology Plan Project (Project No.: 2018A011) Construction of an Open Industrial Innovation System under the Background of Functional Urban Specialization - Based on Industry Analysis and Research in Qingyuan. direction of future industrial upgrading and consumption structure transformation. Building a modern economic system requires strengthening the coordinated development of the real economy and human resources. The construction of a modern vocational education system characterized by deep integration of production and education will continuously optimize the supporting role of human resources in the development of the real economy. The main task of higher vocational colleges is to provide high-level applied talents for regional economic and social development. Higher vocational colleges need to constantly adjust and optimize their professional structure to achieve dynamic and coordinated development with regional industrial structure. Otherwise, it will lead to social problems such as shortage of talents and structural unemployment. Therefore, the industrial development planning and industrial restructuring in the regional economy are the basis for the professional adjustment and talent training model reform in higher vocational colleges.

Since the release of the National Outline for Medium and Long-Term Education Reform and Development Program (2010-2020) in July 2010, the connection between the professional setting of higher vocational colleges and the industrial structure has become a hot topic in the field of education. Hao Fujin and Cai Ruilin (2012), based on five higher vocational colleges in the Changzhou's Education Park, conducted an empirical research on the three indicators of graduate employment rate, job suited rate and the professional-industry structure deviation to the coincidence degree between professional settings of the five vocational colleges and Changzhou's industrial structure. The research results showed that the professional settings are highly deviated from the industrial structure, especially in the modern service industry. Cai Ruilin et al. (2012) also used the five higher vocational colleges in Changzhou as the research sample to construct the professional setting and industrial structure synergy index. The index shows the professional setting is coordinated with the secondary and tertiary industries but it is seriously mismatched with the 
primary industry; Zhao Lei and Liu Xiaoming (2013) used the statistic about the professional settings of higher vocational colleges in Zhejiang Province in 2010 and 2012 to carry out a correlation analysis between the professional settings and industrial structure of Zhejiang Province. The analysis showed: there is a great correlation between its professional settings and the argriculture of primary industry; the correlation with pastoral, forestry, fishery and secondary industries is low; it seriously exceeded the adaptive ratio with the tertiary industry.

Most of the existing literatures use other provinces and municipalities to study the degree of coincidence between professional structure of higher vocational colleges and the local industrial structure. There are relatively few relevant research based on Guangdong data. According to the professional setting data of higher vocational colleges in Guangdong Province, Li You (2009) pointed out that the professional settings have problems such as disconnection between supply and demand and professional quality decline. The reasons lie in blind expansion of similar specialties, unfair competition among schools, and etc.; Chen Jichun (2015) used the vocational colleges of nine cities in the Pearl River Delta as a sample to set up the deviation index of professional structure and industrial structure for evaluating the professionalism degree between higher vocational colleges and regional economic development. The research results showed that the professional setting of higher vocational colleges in the Pearl River Delta region is more consistent with the primary industry in the region than with the secondary and the tertiary industry, which are characterized by the shortage and the overwhelming of different professional settings. Tao Hong and Liao Huiqin (2016), based their research on the current situation of the professional settings of 76 higher vocational colleges in Guangdong Province in 2014 and found that the professional settings are duplicated and not compatible with the industrial structure, therefore, they cannot quickly adapt to the adjustment and upgrading of the industrial structure. Zhou Qiliang (2017) took the higher vocational colleges in West Guangdong as a sample to analyze the data of their professional settings and industrial structure, the results showed that professional setting there was repeated and homogeneous, the coincidence degree between professional structure and industrial structure needs to be further improved.

By looking through the existing literature, it is found that most of the current literature mainly based its analysis of the relationship between professional setting and industrial structure in higher vocational colleges on statistical data, but no literature was on the perspective of urban agglomeration functional specialization. There is still a gap in the research. The Pearl River Delta urban agglomeration is one of the most developed and dynamic urban agglomerations in China. It is of great practical significance to study the relationship between professional structure and industrial structure based on the functional specialization of urban agglomerations. In view of this, this paper attempts to measure the level of higher vocational colleges' professional-industry conformity in the Pearl River Delta urban agglomeration from the perspective of urban function specialization, and combines the level of synergy between professional structure and industrial structure to comprehensively analyze the current situation. The synergy relationship between professional scale and economic structure of talent training in higher vocational colleges provides theoretical and empirical basis for the deep integration of higher vocational education and regional economic and social development in the Pearl River Delta urban agglomeration and for the construction of a modern vocational education system.

\section{MEASUREMENT AND ANALYSIS OF THE MATCHING LEVEL OF PROFESSIONAL SETTING AND INDUSTRIAL STRUCTURE IN HIGHER VOCATIONAL EDUCATION}

In order to analyze the matching level between the professional setting of higher vocational education and the local industrial structure, the "professional-industrial synergy coefficient" is used, which is the ratio between "professional scale/total number of students" and "the number of employees in the industry/the total number of employees". The formula for $i$ major catogory is as follows:

$$
H_{i c}=\left(S_{i} / S_{t}\right) /\left(L_{i} / L_{t}\right)
$$

Among them, ${ }_{i c}$ representing the professional-industry synergy coefficient, ${ }^{S_{i}}$ indicating the number of people in $i_{\text {major category of the region, }} S_{t}$ indicating the total number of higher-vocational students trained in the region, $L_{i}$ indicating the number of employees in the industry related to major catogory $i$ in the region, $L_{t}$ indicating the total number of employed people in the region. If $H_{i c}>1$, it means that exceeded number of talents were trained in category $i$ of that region, while $H_{i c}<1$, it means that too few talents were trained; the closer the coefficient $H_{i c}$ is to 1 , the scale of talent trained in category $i$ in that region met the regional need for the corresponding industry practitioners. The formula for calculating the deviation degree of the regional higher vocational profession-industry synergy coefficient is as follows:

$$
D_{c}=\left|\overline{H_{i c}-1}\right|
$$

The smaller the number $D_{c}$ was, the higher the coincidence degree between higher vocational education and industrial structure in the region, and thus the higher vocational education and the local industry developed synergistically. Referring to the industry classification in the statistical yearbook and the regional economic database, the data of the Higher Vocational Education Quality Annual Report and the Guangdong Statistical Yearbook are used to measure the coincidence level between professional and industrial structure at different levels of cities within the Pearl River Delta urban agglomeration. Among them, Guangzhou and Shenzhen are the central cities of the Pearl River Delta urban agglomeration, and the seven Pearl River Delta cities such as Foshan, Dongguan, Zhuhai, Huizhou, 
Zhongshan, Jiangmen and Zhaoqing are secondary cities (or sub-core cities), and the remaining 12 cities in East and West of Guangdong province are the peripheral cities of the Pearl River Delta urban agglomeration.

TABLE I. HighER-VOCATIONAL PROFESSIONAL-INDUSTRY Synergy CoEfFicient Calculation Results in Pearl River Delta URBAN AGGLOMERATION

\begin{tabular}{|c|c|c|c|c|}
\hline \multirow[b]{2}{*}{ Industries } & \multicolumn{4}{|c|}{ Professional-industry Synergy Coefficient } \\
\hline & $\begin{array}{l}\text { Central } \\
\text { cities }\end{array}$ & $\begin{array}{l}\text { Secondary } \\
\text { cities }\end{array}$ & $\begin{array}{l}\text { Peripheral } \\
\text { cities }\end{array}$ & $\begin{array}{c}\text { The whole } \\
\text { Urban } \\
\text { agglomerat } \\
\text { ion }\end{array}$ \\
\hline $\begin{array}{l}\text { Agriculture, } \\
\text { forestry, animal } \\
\text { husbandry and } \\
\text { fishery }\end{array}$ & 8.5262 & 4.5177 & 0.0857 & 2.0723 \\
\hline Mining & - & - & - & - \\
\hline Manufacturing & 0.1733 & 0.2836 & 0.0780 & 0.2962 \\
\hline $\begin{array}{l}\text { Production and } \\
\text { supply of } \\
\text { electricity, heat, } \\
\text { gas and water }\end{array}$ & 0.7476 & 0.4022 & 0.0000 & 0.6156 \\
\hline Construction & 0.8200 & 2.0078 & 0.1589 & 1.5554 \\
\hline $\begin{array}{lr}\text { Economics } & \text { and } \\
\text { Trade (Wholesale } \\
\text { and } & \text { Retail, } \\
\text { Financial, } & \text { Real } \\
\text { Estate, Leasing } \\
\text { and } \\
\text { Services) }\end{array}$ & 1.6902 & 7.6070 & 1.1987 & 5.0111 \\
\hline $\begin{array}{l}\text { Transportation, } \\
\text { warehousing and } \\
\text { postal services }\end{array}$ & 0.0662 & 0.2591 & 0.0000 & 0.1471 \\
\hline $\begin{array}{l}\text { Accommodation } \\
\text { and catering }\end{array}$ & 0.5149 & 4.3580 & 0.3411 & 1.9205 \\
\hline $\begin{array}{l}\text { Information } \\
\text { transmission, } \\
\text { software } \\
\text { information and } \\
\text { technology } \\
\text { services }\end{array}$ & 2.1976 & 15.2098 & 1.9837 & 6.8358 \\
\hline $\begin{array}{l}\text { Scientific research, } \\
\text { technical service }\end{array}$ & - & - & - & - \\
\hline $\begin{array}{l}\text { Water, } \\
\text { environmental and } \\
\text { public facilities } \\
\text { management }\end{array}$ & 0.3808 & 0.0000 & 0.0338 & 0.4417 \\
\hline $\begin{array}{l}\text { Resident services, } \\
\text { repairs and other } \\
\text { services }\end{array}$ & 0.0000 & 0.0000 & 0.0000 & 0.0000 \\
\hline Education & 1.0837 & 1.4391 & 0.3382 & 2.0310 \\
\hline $\begin{array}{l}\text { Health and social } \\
\text { work }\end{array}$ & 0.0000 & 5.1366 & 0.1122 & 1.6197 \\
\hline $\begin{array}{l}\text { Culture, sports and } \\
\text { entertainment }\end{array}$ & 7.8580 & 15.8188 & 1.7124 & 15.9521 \\
\hline $\begin{array}{l}\text { Public } \\
\text { administration, } \\
\text { social security and } \\
\text { social organization }\end{array}$ & 0.1741 & 0.3271 & 0.0382 & 0.3062 \\
\hline
\end{tabular}

"Table I" shows the results of $H_{i c}$ the higher-vocational professional-industry synergy coefficient of the center, secondary, peripheral cities and the whole region of the Pearl River Delta urban agglomeration. Based on the mobility of human resources, the coefficient of the whole region can objectively reflect the matching condition between the overall talent training scale in the region and the employment demand of the industry. $D_{c}$ as the deviation degree of the professional-industry synergy coefficient of the cities in the Pearl River Delta urban agglomeration is generally high, reflecting the low coincidence between the professional structure of higher vocational colleges and the needs for regional industrial personnel, which means that the training of professional talents in higher vocational education in the region does not match the regional need for industrial talents. From the comparative analysis of coefficients amongst various industry classification, the professional-industry synergy coefficient of agriculture, forestry, animal husbandry and fishery, economic and trade, information technology and cultural and sports industries in the urban agglomeration is obviously high, and their scale of professional personnel training is supersaturated, among which, $D_{c}$, the deviation degree of information and clutural industries is 5.8358 and 14.9251 respectively, therefore, the scale of professional talent training is much larger than the need of regional industry. The synergy coefficient of construction industry, accommodation and catering industry, health and social work industry is close to 1 , an ideal state, which means the scale of talent cultivation is moderately saturated. However, the synergy coefficient of manufacturing, power, heat, gas, transportation, water conservancy and public management is far less than 1, which shows that the scale of personnel training is in an unsaturated state, failing to meet the human resources need of regional industries; most of the industryrelated majors in these industries are majors in science and engineering, which reflects the large gap between the number of students trained in higher vocational schools and the industry demand. From the perspective of the professional-industry synergy coefficient of the education industry, the synergy coefficient of the central cities and the secondary cities are slightly higher than 1 , the education talent training scale is moderately saturated; the synergy coefficient of the peripheral cities is only 0.3382 , which means a large gap in the number of education professional training cannot meet the need of the educational development in these regions.

Have been compared from the perspective of the values of the cities at different levels in the region, the synergy coefficient of each industry category in the central cities and the secondary cities is higher than that in the peripheral cities. Obviously, the scale of higher vocational talent training in peripheral cities in the Pearl River Delta urban agglomeration is much smaller than that of the central and secondary cities. This is consistent with the current distribution of higher vocational colleges and reflects the unbalanced development of higher vocational education in the region. The resources of higher vocational education in the Pearl River Delta urban agglomeration are mainly concentrated in the core area, namely the Pearl River Delta cities. The synergy coefficient of the peripheral cities located in the eastern and western parts of Guangdong is relatively small. Except for the economic and trade, information, culture and sports industries, whose synergy coefficient is 
close to 1 , their talent cultivation is moderately saturated; and the synergy coefficient of other industries is less than 1, their talent cultivation is in an unsaturated state. Combined with the analysis of functional specialization and synergy coefficient of cities at each level, the current higher vocational professional structure systems do not meet the needs of the functional specialization development within the urban agglomeration, which means the situation of professional structure and the urban function positioning is misplaced. According to the theory of functional urban specialization, the central cities of the urban agglomeration should be positioned as management and R\&D function, focusing on the development of the headquarters economy and the modern service industry, which should gather highly gather knowledge-intensive management and R\&D talents; the positioning of secondary cities is advanced emerging strategic manufacturing, which should gather advanced manufacturing talents; peripheral cities should be positioned as manufacturing, parts assembly and warehousing and procurement, which should mainly gather manufacturing, logistics and warehousing professionals. Therefore, the focus of higher vocational talent training in central cities is the economic and trade professions in the wholesale and retail, financial, real estate, leasing and business services industries, as well as education, public administration, social security and social organizations. However, in the current professional structure of the central cities, the synergy coefficient of these majors is not high, and even in some cities it is really low. Instead, we should focus on the development of manufacturing industry in secondary and peripheral cities. But the professionalindustry synergy coefficient of the manufacturing industry is far less than 1, which is in an unsaturated state. The scale of manufacturing personnel training is far from meeting the demand for the manufacturing jobs in these two types of cities. Among them, the manufacturing-industry synergy coefficient of peripheral cities is only 0.0780 , showing a serious shortage of manufacturing talents.

\section{ANALYSIS ON THE STATUS QUO OF INDUSTRIAL STRUCTURE, Higher VocATIONAL ProfESSIONAL STRUCTURE AND GRADUATE EMPLOYMENT REGIONAL STRUCTURE IN PEARL RIVER DELTA URBAN AGGLOMERATION}

In order to reflect more scientifically the coincidence level between professional setting and industrial structure in a region, and to explore the direction suitable for the dynamic adjustment of the professional structure in the Pearl River Delta urban agglomeration, this paper, combined with the industrial structure adjustment direction of the Pearl River Delta urban agglomeration and the construction target of modern economic system, conducted a comprehensive analysis.

\section{A. There Is Functional Specialization Tendency Within} Pearl River Delta Urban Agglomeration, and the Industrial Structure Is Continuously Optimized and Adjusted

Since the reform and opening up, the Pearl River Delta urban agglomeration has become a world-famous processing, manufacturing and export base. It is one of the most developed, dynamic, and export-oriented economies in China, and one of the most active urban clusters participating in the global value chain. The three industrial scales of the Pearl River Delta urban agglomeration continue to grow, and the industrial structure is adjusted and optimized. The growth rate of the total output of the secondary and tertiary industries, especially the tertiary industry, is significantly higher than that of the primary industry (as shown in "Fig. 1" and "Fig. 2").

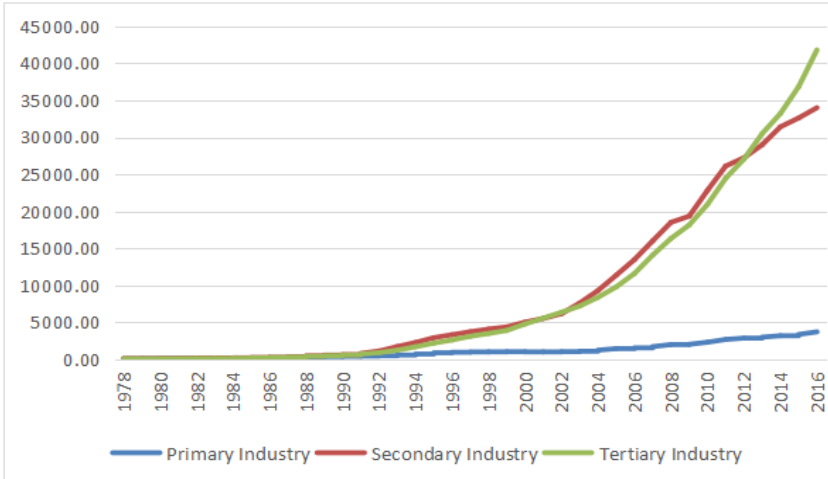

Fig. 1. Trends in the total volume of three industries in the Pearl River Delta urban agglomeration.

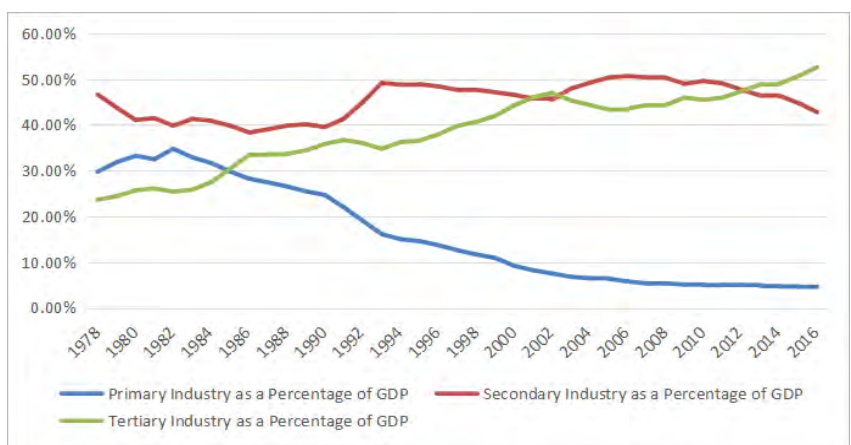

Fig. 2. Trends of the three industries as a percentage of the GDP in the Pearl River Delta urban agglomeration from 1979 to 2016.

Since the 18th National Party Congress, Guangdong has focused on improving the quality and efficiency of the supply system, adjusting the industrial structure, and developing and improving the modern industrial system. The 19th National Congress of the Communist Party of China first proposed the concept of "modernized economic system" and clarified the connotation for the construction of modern economic system, namely the economic system, the modern industrial system and the dynamic system. Among them, the construction of modern industrial system focuses on "real economy, technological innovation, modern finance, and coordinated development of human resources". The main features include high-quality supply system, innovative 
society, regional coordinated development and new pattern of all-around opening up. At the same time, the report of the 19th National Congress mentioned that it is necessary to "build urban structure in which large, medium, and small cities will become the mainstays of the urban agglomerations and small towns will develop coordinatively with the mainstays." At present, in order to promote regional coordinated development between the core areas and the peripheral areas of North, East and West Guangdong, the Pearl River Delta urban agglomeration is rebuilding the innovation space and industrial layout, promoting the Pearl River Delta cities with industrial clusters such as professional towns and industrial transfer parks as the carriers and developing industrial co-construction in the center-peripheral cities. This shows that the Pearl River Delta urban agglomeration, conforming to the development law of international regional division, gradually form a functional specialization division model based on the value chain. In terms of modern industrial construction, the Pearl River Delta urban agglomeration is striving to promote the rapid development of new-generation communication, biomedicine, new energy vehicles and other strategic emerging industries with independent innovation.

\section{B. The Professional Structure of Higher Vocational Education Is Continuously Optimized, but It Still Does Not Match with the Industrial Structure}

Under the background of constructing the modern economic system, modern human resources and industrial systems are required to develop in a coordinated manner. As of 2017, the Pearl River Delta urban agglomeration has basically formed a professional structure based on seven major categories of intelligent manufacturing, electronic information, modern productive services, civil engineering, cultural creativity, modern life services, and medical and health.["Annual Report on the Quality of Higher Vocational Education in Guangdong Province", 2018.] However, from the comparison of the scale structure of the professional training of the higher vocational education in the Pearl River Delta urban agglomeration in 2017 and the proportion of the three industries in the region (as shown in "Fig.3"), the professional structure of higher vocational education still does not match the current industrial structure. The deviation in the secondary and tertiary industries is particularly obvious. Especially there is insufficiency in the talent cultivation of the secondary industry, whose proportion is only $30.84 \%, 12.16 \%$ lower than the secondary industry proportion $43 \%$. While the proportion of higher vocational talents training scale in the tertiary industry is $15.79 \%$ higher than the regional tertiary industry's total production value.

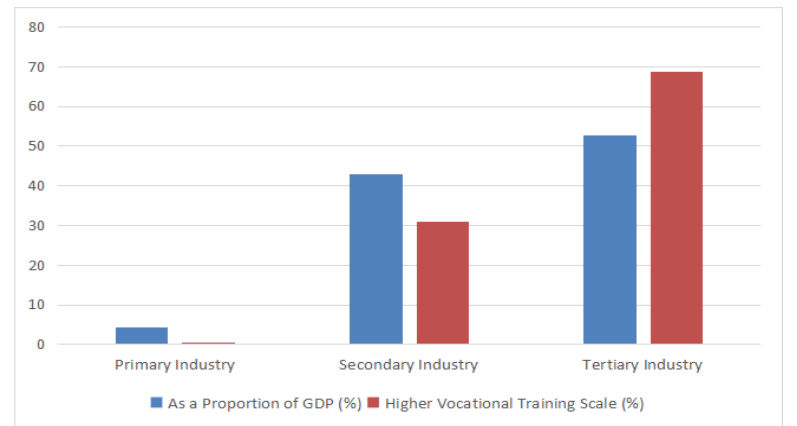

Fig. 3. Comparison of the three industrial structures and higher vocational structure of the Pearl River Delta urban agglomeration in 2017.

${ }^{\text {a. }}$ Source: Statistics Bulletin of Guangdong National Economic and Social Development in 2017.

\section{The Higher Vocational Professional Structure Are}

Inconsistent with the Graduate Employment Flow, and It Is Difficult to Accurately Meet the Local Industrial Needs

Judging from the employment distribution of higher vocational graduates in the Pearl River Delta urban agglomeration, we will find that the employment direction is too concentrated in the center and secondary cities, only a few higher vocational graduates in North, East and West Guangdong works in the locality of the college after graduation (as shown in "Table II" and "Fig. 4"). On average, $18.63 \%$ of the graduates in the peripheral cities stay in the location of the college, and most of the rest flow to the Pearl River Delta region. Taking the on-campus job fair 2018 in the North Guangdong as an example, more than 11,000 job offers provided by 430 companies only recruited about 3,110 students for employment or internship. It can be seen that when the higher vocational colleges in the urban agglomeration strive to adjust the professional structure dynamically according to the local industrial structure, most of the students trained are employed in other places. Then, it is futile for local colleges to adjust the professional structure to the local industry. This will increase the difficulty of dynamically connecting professional structures and industrial structures in the region, which is not conducive to the coordinated development of human resources and economic systems. In the case that the resources of higher vocational education are insufficient, the total amount of higher vocational talents in the peripheral cities is more difficult to meet the needs of local industry development for high-level applied talents. 
Table II. Regional Distribution of Employment Direction of Graduates in the Peripheral Cities of the Pearl River Delta Urban AGGLOMERATION

\begin{tabular}{|c|c|c|c|c|c|}
\hline Region & Cities & $\begin{array}{c}\text { Higher } \\
\text { Vocational } \\
\text { College }\end{array}$ & $\begin{array}{c}\text { Work in } \\
\text { the School } \\
\text { Location }\end{array}$ & $\begin{array}{l}\text { Work in the } \\
\text { Core \& } \\
\text { Secondary } \\
\text { Cities }\end{array}$ & $\begin{array}{c}\text { Work in } \\
\text { Other } \\
\text { Places }\end{array}$ \\
\hline \multirow[b]{2}{*}{ North Guangdong } & Qingyuan & $\begin{array}{l}\text { Qingyuan } \\
\text { Polytechnic }\end{array}$ & $15.39 \%$ & $76.84 \%$ & $7.77 \%$ \\
\hline & Shaoguan & $\begin{array}{l}\text { Guangdong } \\
\text { Songshan } \\
\text { Polytechnic }\end{array}$ & $2.38 \%$ & $84.68 \%$ & $12.94 \%$ \\
\hline \multirow{4}{*}{ West Guangdong } & Yangjiang & $\begin{array}{l}\text { Yangjiang } \\
\text { Polytechnic }\end{array}$ & $12.50 \%$ & $64.03 \%$ & $23.47 \%$ \\
\hline & Zhanjiang & $\begin{array}{l}\text { Guangdong } \\
\text { Institute of } \\
\text { Arts and } \\
\text { Sciences }\end{array}$ & $4.67 \%$ & $67.19 \%$ & $28.14 \%$ \\
\hline & Maoming & $\begin{array}{l}\text { Maoming } \\
\text { Polytechnic }\end{array}$ & $10.95 \%$ & $53.54 \%$ & $35.51 \%$ \\
\hline & Yunfu & $\begin{array}{l}\text { Luoding } \\
\text { Polytechnic }\end{array}$ & $19.85 \%$ & $69.56 \%$ & $10.59 \%$ \\
\hline \multirow{5}{*}{ East Guangdong } & Shangwei & $\begin{array}{l}\text { Shanwei } \\
\text { Polytechnic }\end{array}$ & $32.25 \%$ & $67.75 \%$ & \\
\hline & Heyuan & $\begin{array}{l}\text { Heyuan } \\
\text { Polytechnic }\end{array}$ & $23.82 \%$ & $67.24 \%$ & $8.94 \%$ \\
\hline & & $\begin{array}{l}\text { Jieyang } \\
\text { Polytechnic }\end{array}$ & $30.47 \%$ & $54.51 \%$ & $15.02 \%$ \\
\hline & Jieyang & $\begin{array}{l}\text { Chaoshan } \\
\text { Vocational } \\
\text { and } \\
\text { Technical } \\
\text { College }\end{array}$ & $27 \%$ & $66 \%$ & $7 \%$ \\
\hline & Shantou & $\begin{array}{l}\text { Shantou } \\
\text { Polytechnic }\end{array}$ & $25.60 \%$ & $50.83 \%$ & $23.57 \%$ \\
\hline
\end{tabular}

Source: Annual Report on the Employment Quality of College Graduates 2016

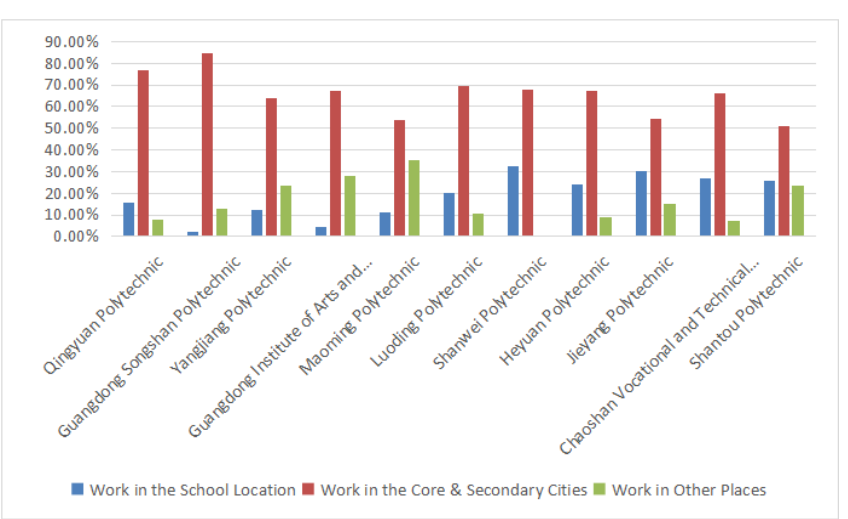

Fig. 4. Comparison of employment distribution of higher vocational graduates in North, West and East Guangdong.

\section{CONCLUSION}

Change from industrial specialization to functional specialization has become the basic development trend of urban division of labor, and a new regional division of labor system has gradually formed. Based on the goal of building a modern economic system, the modern vocational education professional structure system must match the existing industrial system and the future industrial development direction of the urban agglomeration. This requires that the higher vocational professional system should be jointed to the dynamic linkage of the industrial system. After constructing the professional-industry synergy coefficient and measuring the higher vocational education in the Pearl River Delta urban agglomeration, combined with the analysis of the industrial structure and adjustment direction of the Pearl River Delta urban agglomeration, the following main conclusions and recommendations are drawn:

- The structural structure system of higher vocational education in the Pearl River Delta urban agglomeration failed to develop coordinatively with the industrial system. The professional structure and the industrial structure are not in good agreement, and the overall manufacturing professional talents in the urban agglomeration are under-cultivated, which is far from meeting the development needs of the modern industrial system characterized by high-end manufacturing and strategic emerging industries. Therefore, it is recommended to dynamically and scientifically monitor the professional-industry synergy development in the region, adjust the professional structure of higher vocational schools in a timely manner, and increase the training scale of professionals in science and engineering, manufacturing, and education.

- The professional structure does not match the urban function positioning within the urban agglomeration. 
The training scale of management and service talents in the central cities cannot meet the urban functional demand. Secondary cities should strengthen high-end manufacturing functions while the peripheral cities of East and West Guangdong should strengthen the functions of manufacturing, assembly, logistics, education and basic public services. However, in these two levels of cities, the training scale of manufacturing and transportation personnel cannot meet the needs, which makes it difficult to support the development of urban functions. The training of talents in higher vocational colleges should conform to the requirements of regional division of labor and coordinated development. The adjustment of professional structure should be oriented to the positioning of urban functions and the adjustment of industrial system.

- The structure of higher vocational professional settings is inconsistent with the employment flow of graduates. The proportion of local students in higher vocational colleges in the peripheral cities of the Pearl River Delta urban agglomeration is relatively low; therefore the number of graduates who work in colleges after graducation is rather small. This has not eased the employment needs of enterprises and institutions in the North, East and West Guangdong, but also influenced the effect of ajusting professional structure to the local industrial demand made by the local higher vocational colleges. In order to promote the accurate integration and linkage development between higher vocational professional structure and industrial structure in the region, and to realize the coordinated development of human resources and industrial system, it is recommended to increase the guiding role of enrollment policy and employment policy such as to increasing the proportion of local students in the enrollment plan of higher vocational colleges in North, East and West Guangdong and encouraging local colleges to train more local students. This is undoubtedly an effective way to retain talents and reduce brain drain.

- The distribution of higher vocational education resources in urban agglomerations is extremely uneven. Higher vocational colleges in the Pearl River Delta urban agglomeration are mainly concentrated in the central and secondary cities. At present, the manufacturing functions in the value chain are continually moving to the peripheral cities. During their integration into the development of the core areas of the Pearl River Delta, the cities in North, East and West Guangdong need more talents with strong practical ability what is closely related to thelocal industrial development. The high concentration of resources in higher vocational education is not conducive to the regional equilibrium and coordinated development of the Pearl River Delta urban agglomeration. It is suggested that the government increase the investment in higher vocational education resources in North, East and
West Guangdong, build a batch of applied undergraduate and higher vocational colleges to ease the urgent need for applied talents in the peripheral areas, optimize the regional resources allocation of higher vocational education to help the construction of modern economic system as well as to promote the coordinated and balanced regional development.

\section{REFERENCES}

[1] Report of the 19th National Congress of the Communist Party of China. 2017-10-18.

[2] Cairuilin, Liu Xia, Long Hui. Research on the Association's Professional Setting and Industrial Structure of Higher Vocational Colleges[ J]. Higher Vocational Education, 2012 (7): 82-85.

[3] Chen Jichun. Research on the Matching Degree Between Professional Setting and Regional Economic Development in Higher Vocational Colleges in the Pearl River Delta Region[J]. Vocational and Technical Education, 2015(5):8-13.

[4] Gu Yu. Path Analysis of Guangdong's Construction of Modern Economic System[J]. Development and Reform Theory and Practice, 2018 (2): 8-11.

[5] HAO Fujin, CAI Ruilin. An Empirical Study on the Matching of Professional Setting and Industrial Structure in Higher Vocational Colleges - Taking Changzhou City as an Example[J]. Journal of Changzhou Vocational College of Information Technology, 2012 (4): 7-10.

[6] Li You. Research on the Adaptability of Professional Structure and Industrial Structure in Guangdong Higher Vocational Colleges[J].Higher Education Exploration, 2009 (3) : 101-104.

[7] Tao Hong, Liao Huiqin. Research on the Connection between Professional Setting and Industrial Structure in Higher Vocational Colleges in Guangdong Province[J]. Vocationaland Technical Education Forum, 2016(18): 40-44.

[8] Zhao Lei, Liu Xiaoming.Study on the Professional Setting and Industrial Structure of Higher Vocational Colleges in Zhejiang Province[J]. Education and Vocation, 2013 (30):21-23.

[9] Zhou Qiliang. Research on the Adaptability of Professional Setting and Industrial Structure in Higher Vocational Colleges in Western Guangdong[J]. Vocational and Technical Education, 2017 (05): 18-23. 